\title{
El uso diario de las pantallas solares redujo el número de nuevos carcinomas espinocelulares
}

Daily sunscreen application and betacarotene supplementation in prevention of basal cell and squamous cell carcinomas of de skin: a randomised trial. A Green, G Williams, R Neale. Lancet 1999;354:723-29.

\section{Objetivo}

Evaluar la eficacia del uso de pantallas solares y suplementación oral de betacarotenos en la prevención del cáncer de piel.

\section{Diseño}

Ensayo clínico aleatorizado, con diseño factorial* ${ }^{*}$ y un seguimiento promedio de 4,5 años.

\section{Lugar}

Residentes de Nambour en el sudeste de Queensland, Australia.

\section{Pacientes}

De 1621 pacientes iniciales, incluyeron 1383 pacientes de la población general que se realizaron el examen dermatológico a los 4,5 años de seguimiento.

\section{Intervención}

Los participantes fueron asignados a cuatro grupos de tratamiento: - aplicación diaria de pantalla solar con factor de protección solar (FPS) 15 en cabeza, cuello, brazos y manos y suplemento de betacaroteno $30 \mathrm{mg}$ día.

- Pantalla solar más tabletas de placebo

- Sólo betacarotenos

- Sólo placebo.

\section{Medición de los resultados principales}

Como resultado final se midió la presencia de cáncer de piel. No se incluyeron aquellos cánceres cutáneos diagnosticados un año luego del inicio del estudio, ya que fueron considerados enfermedad latente presente al inicio del mismo.

\section{Resultados principales}

El análisis fue por intención de tratar. * De los 1383 pacientes, se encontraron 789 nuevos cánceres de piel en 256 participantes durante el período de seguimiento. Los dos tumores más frecuentemente encontrados fueron carcinomas basocelulares y espinocelulares. Los análisis efectuados se refirieron exclusivamente a estos dos tipos principales. El efecto de la aplicación diaria de pantalla solar se analizó considerando los cánceres que ocurrían exclusivamente en los sitios donde la pantalla solar era aplicada.

No se observaron diferencias significativas en la incidencia de nuevos cánceres en los que recibieron pantalla diaria vs. los que no la recibieron: basocelular, 2588 vs 2509 por 100.000 ; RR 1,03 (IC 95\% 0.73-1.46); espinocelular 876 vs 996 por 100.000; RR 0.88 (IC 95\% 0.50-1.56). Tampoco hubo diferencias en la incidencia de ambos tipos de cánceres en los pacientes que recibieron betacaroteno. El único beneficio que se observó fue la reducción del número total de carcinomas espinocelulares en los pacientes que utilizaron pantalla diaria, (1115 vs 1832 por 100.000), lo que implica un riesgo relativo de 0,61 (IC 95\% 0,46 a 0,81 ). El beneficio fue mayor en los pacientes con antecedentes de espinocelular previo.

\section{Conclusiones}

El carcinoma espinocelular, no así el basocelular, parece ser plausible de prevención a través del uso rutinario de pantalla solar. Los betacarotenos no demostraron beneficio en ninguno de los dos tipos de cáncer de piel.

\section{Comentario}

El presente estudio demuestra la probable utilidad del uso de pantalla solar en la prevención del carcinoma espinocelular. Aunque la diferencia en la aparición de nuevos tumores fue pequeña y no significativa, de alrededor de un $12 \%$; las pantallas redujeron el número total de carcinomas espinocelulares en forma significativa. Los resultados del, estudio son explicables teniendo en cuenta la mayor influencia de la luz ultravioleta en la génesis del epitelioma espinocelular que en el del basocelular. No obstante, hasta el momento, no ha sido descartada su asociación. El hecho de no haber hallado disminución de la incidencia del epitelioma basocelular podría deberse a que la prevención debería hacerse desde una edad más temprana y con un tiempo de seguimiento más prolongado que el realizado por este trabajo.

Es importante señalar que la pantalla utilizada en el presente estudio fue de un factor de protección solar (FPS) de 15 (el mínimo recomendado), y hoy se encuentran ampliamente disponibles pantallas con FPS mucho mayores. Como existe un gradiente dosis-respuesta entre los rayos ultravioletas y el carcinoma (especialmente espinocelular), ${ }^{1}$ es posible que a mayor protección solar, mayor sea la prevención tumoral.

Otros factores, importantes a considerar en futuros estudios, son la influencia del tipo cutáneo, del nivel de exposición a la luz ultravioleta, de lesiones premalignas previas, del fotodaño previo, y también de otros factores predisponentes concomitantes (como por ejemplo: inmunosupresión). ${ }^{2}$

Este estudio es el primero en aportar evidencia acerca del efecto de la pantalla solar a largo plazo. El efecto benéfico en la prevención de cáncer espinocelular, de ser confirmado en otros estudios, haría más fuerte la recomendación del empleo de protector solar (junto a la valoración del uso de la sombra estructural) como medidas preventivas de bajo costo y alto beneficio en relación a la prevención del cáncer de piel. ${ }^{3}$

\section{Referencias}

1. Rosso S, Zanetti R, Martínez C y cols. The multicentre South European study Helios II: different sun exposure patterns in the aetiology of basal cell and squamous cell carcinomas of the skin. Br J Cancer 1996; 73:1447-54

2. Friedman R, Rigel D, Kopf A, Harris M, Baker D., Cáncer de piel. Editorial Médica Panamericana

1993. Bs As . Argentina.

3. Robinson J, Darrell S, and Amonette R. Summertime sun protection used by adults for their children. $\mathrm{J}$

Am Acad Dermatol 2000; 42: 746-53. 